\title{
Monitoramento e avaliação de aspectos relacionados à compostagem de lodo de abatedouro de frangos
}

\author{
Alexandre Couto Rodrigues', Aline Hass², Cristiane Bozzetto ${ }^{3}$, Giovana Garlet ${ }^{4}$, Luciana Gregory Ritter ${ }^{5}$, \\ Sabrina Rodrigues da Conceição ${ }^{6}$, Vanessa Deisi Renz ${ }^{7}$
}

'Professor Doutor,Universidade Federal de Santa Maria, Frederico Westphalen, RS, Brasil

2, 3, 5, 6,7 Graduandos, Universidade Federal de Santa Maria, Frederico Westphalen, RS, Brasil

\section{Resumo}

Devido ao grande crescimento da produção de frangos e consequentemente aumento na geração de resíduos busca-se formas de alternativas para o tratamento de resíduos gerados na avicultura de corte, de modo a buscar um desenvolvimento sustentável que vise à preservação ambiental e a expansão comercial. A compostagem surge como uma alternativa viável e de baixo custo para o tratamento desses resíduos proveniente de abatedouros de frango. O experimento foi instalado no campus da Universidade Federal de Santa Maria - UFSM na cidade de Frederico Westphalen - RS, onde objetivou-se avaliar a eficiência da compostagem através do monitoramento da temperatura e avaliação de parâmetros como: moscas, insetos, larvas, minhocas e odor. Com relação aos resultados obtidos verificou-se a maior temperatura registrada de $59^{\circ} \mathrm{C}$. A intensa presença de moscas em todas as leiras logo após a instalação das mesmas. Observou-se também que na fase mesófila e início da fase termófila, as moscas permaneceram por maior período no ambiente. As larvas foram verificadas somente na fase inicial de compostagem, desaparecendo após passar pela fase termófila. A compostagem está na fase criófila, com apenas a presença de minhocas e insetos.

Palavras-chave: avicultura; compostagem; resíduo sólido; 


\section{INTRODUÇÃO}

Segundo dados da União Brasileira de Avicultura (2011) o Brasil encerrou o ano de 2011 como o $3^{\circ}$ maior produtor de frangos, onde houve uma produção de 13,058 milhões de toneladas representando $15,3 \%$ da produção mundial.

O setor avícola nacional, após alto investimento nos elos da cadeia produtiva, sofreu uma acelerada expansão da criação e consequentemente o aumento no despejo de resíduos provenientes das indústrias de processamento das aves. Esses resíduos são denominados de água residuária ou efluente de abatedouro avícola e caracterizam-se pelo elevado teor de matéria orgânica e carga patogênica, representando desta maneira um material de alto poder poluente. (SUNADA, 2011).

O descarte desses lodos no meio ambiente, sem que tenham sofrido algum tipo de tratamento prévio, podem levar a sérios problemas de contaminação química e microbiológica do solo e da água.

Neste sentido, a compostagem constitui-se como alternativa viável, de baixo custo e sanitariamente eficiente na eliminação de patógenos de resíduos sólidos submetidos a este método. Trata-se de um processo aeróbio controlado, em que diversos microrganismos são responsáveis, por transformações bioquímicas na massa de resíduos e humificação. É um processo eficaz de reciclagem da fração putrescível dos resíduos sólidos, com vantagens econômicas, pela produção do composto, aplicável na agricultura, ótimo para a contenção de encostas e para o combate da erosão, etc. (OLINTO, 2012).

\section{OBJETIVOS}

Avaliar a eficiência do processo de compostagem para destinação final ambiental correta do lodo de abatedouro de frangos.

Monitorar as fases da compostagem através da temperatura.

Monitorar e avaliar parâmetros como moscas, insetos, larvas, minhocas e odor, caracterizando cada fase da compostagem e a eficiência do processo.

\section{METODOLOGIA}

O experimento foi instalado no campus da Universidade Federal de Santa Maria - UFSM na cidade de Frederico Westphalen - RS, localizada a uma latitude $27^{\circ} 21^{\prime} 33^{\prime \prime} \mathrm{S}$, longitude $53^{\circ} 23^{\prime} 40^{\prime \prime}$ $\mathrm{O}$ e altitude de 566 metros.

Primeiramente preparou-se o local, nivelando o terreno. E impermeabilizando o solo com lonas plásticas, devidamente dimensionadas, fazendo canaletas ao redor para protegê-las das enxurradas.

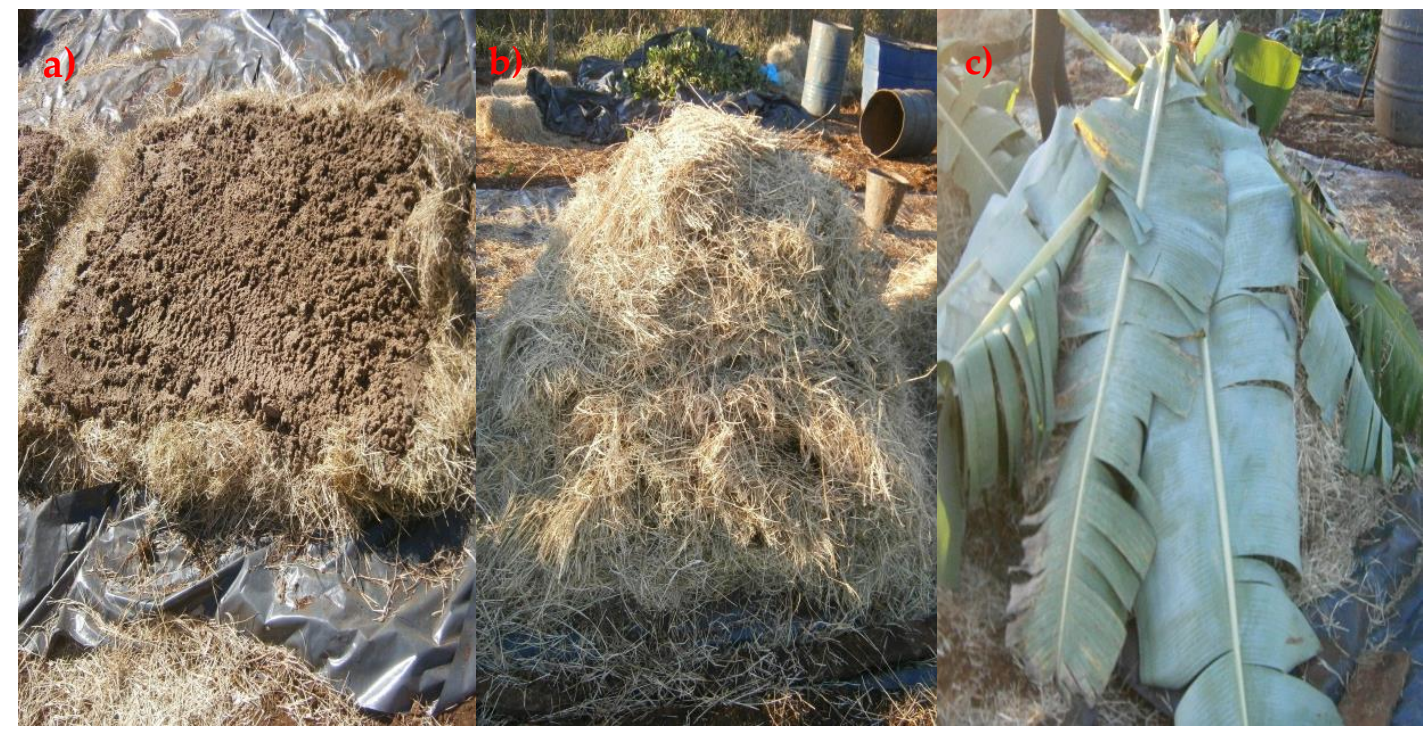

Figura 1- Leiras de Compostagem, Frederico Westphalen - RS, 2013. a)Etapa inicial; b)Aspecto final das leiras; c)Cobertura das leiras; 
Em seguida foram construídas 3 leiras de compostagem, com dimensões: base de 1,5m x 1,5m, altura de $1,5 \mathrm{~m}$. O composto utilizado foi o lodo do Abatedouro de Frangos Piovesan Ltda, e como fonte de carbono para o processo foi utilizado feno de grama tifton, na proporção de $15 \mathrm{~cm}$ de feno e após $5 \mathrm{~cm}$ de resíduo como ilustra a figura 1-a, até atingir a altura de 1,5 metro. Em cada camada de lodo pulverizou-se o composto Enzilimp (que auxilia na biodegradação), sendo que a última camada foi formada pelo feno da grama tifton, conforme figura 1-b. Para evitar a perda de umidade das leiras, as mesmas foram cobertas com folhas de bananeiras, conforme figura 1-c, a cada revolvimento.

Em média, cada leira foi implantada com $110 \mathrm{~kg}$ de lodo, $56 \mathrm{~kg}$ de feno e 190 litros de água sem cloro. O controle da umidade está sendo mantido com auxílio de irrigação realizada com a mangueira nos dias de revolvimento. A temperatura foi monitorada semanalmente, com o auxílio de um termômetro de álcool nas seguintes profundidades e alturas: Ponto 1: altura de $20 \mathrm{~cm}$ e profundidade de $20 \mathrm{~cm}$; Ponto 2: altura de $20 \mathrm{~cm}$ e profundidade de $50 \mathrm{~cm}$; Ponto 3: altura de $40 \mathrm{~cm}$ e profundidade de $20 \mathrm{~cm}$; Ponto 4: altura de $60 \mathrm{~cm}$ e profundidade de $20 \mathrm{~cm}$.

Os seguintes parâmetros: moscas, insetos, larvas, minhocas e odor também foram monitorados semanalmente. Para avaliar essas variáveis qualitativas atribuem-se notas de acordo com a intensidade, conforme tabela 1.

Tabela 1. Classificação do parâmetro (moscas, larvas, insetos, minhocas e odor) de acordo com a intensidade.

\begin{tabular}{cc}
\hline $\begin{array}{c}\text { Intensidade do } \\
\text { parâmetro }\end{array}$ & Classificação \\
\hline Ausência & 0 \\
Pouco & 1 \\
Médio & 2 \\
Elevado & 3 \\
Muito elevado & 4 \\
\hline
\end{tabular}

O experimento foi implantado no dia 17 de abril de 2013, sendo que as leiras sofreram seis revolvimentos, sendo o primeiro após 10 dias, o segundo após 22 dias, o terceiro após 37 dias, o quarto após 55 dias, o sexto após 72 dias e o sexto 90 dias após a implementação do experimento, para acelerar o processo de decomposição, com o aumento da aeração.

\section{RESULTADOS E DISCUSSÃO}

O presente trabalho encontra-se em andamento, com aproximadamente 97 dias de monitoramento, com uma previsão de 120 dias para a conclusão.

$\mathrm{Na}$ compostagem, inicialmente, atuam microrganismos que metabolizam o nitrogênio orgânico transformando-o em nitrogênio amoniacal e com o decorrer da decomposição, a amônia pode ser perdida por volatilização.

No processo de compostagem as energias produzidas pelos microrganismos promovem incremento de temperaturas. Quando essas se encontram superiores a $40^{\circ} \mathrm{C}$ começam a predominar os microrganismos termofílicos, responsáveis pela decomposição acelerada da matéria orgânica. Nessa fase as temperaturas ultrapassam os $55^{\circ} \mathrm{C}$, promovendo a eliminação dos microrganismos patogénicos para os humanos ou para as plantas. Acima dos $65^{\circ} \mathrm{C}$ a maioria dos microrganismos serão eliminados, incluindo aqueles que são responsáveis pela decomposição, necessitando assim controlar as tempera- 


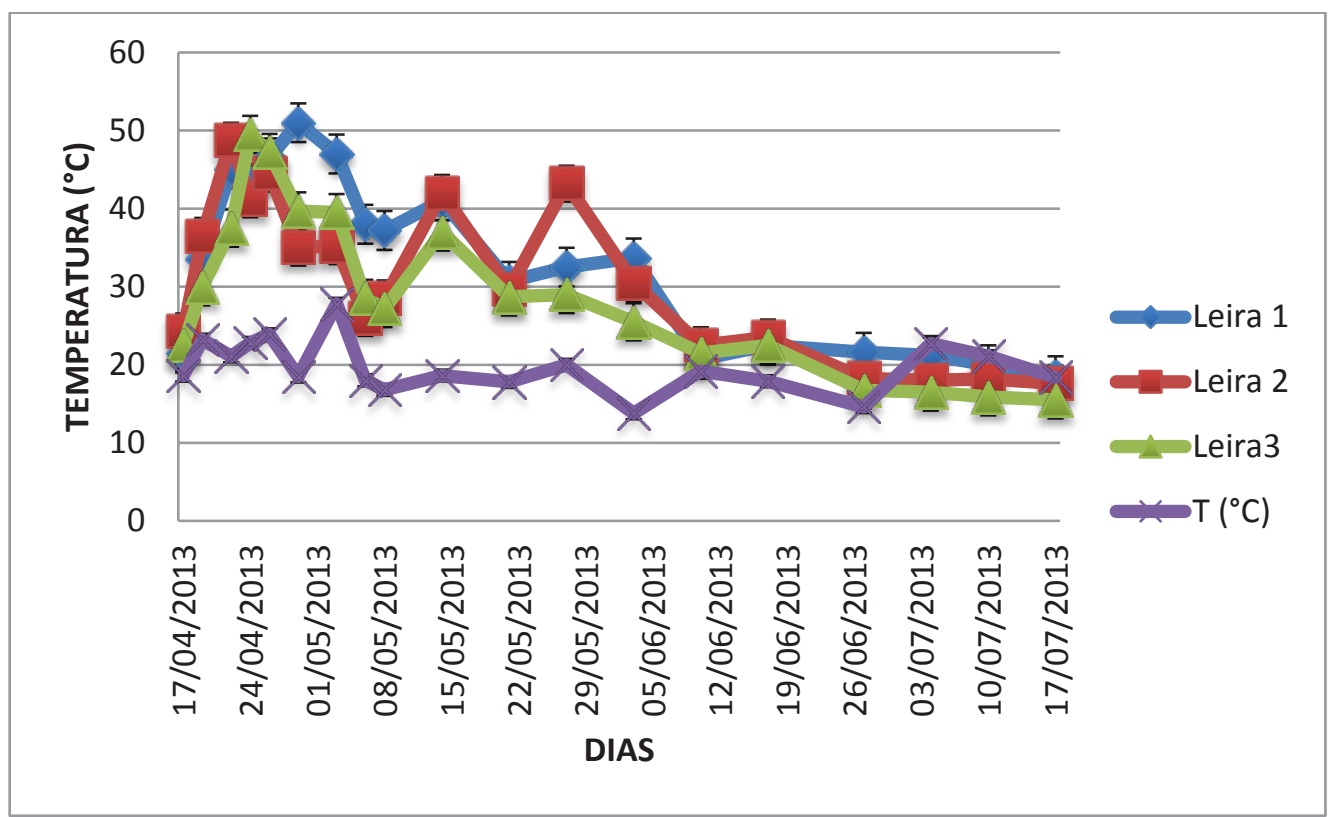

Figura 2: Temperaturas médias.

turas com umidade e aeração mantendo a níveis desejados (OLIVEIRA et al,2008).

Ao longo do processo de compostagem foram registradas as temperaturas. Na figura 2, observam-se as temperaturas médias de cada leira bem como a temperatura ambiente (INMET).

Cerca de dois dias após a instalação do experimento pode ser observado acréscimos considerados na temperatura das leiras, que diminui com a estabilização da matéria orgânica pelos organismos. Segundo KIEHL (1998), a temperatura é o fator mais indicativo do equilíbrio biológico, influenciando diretamente no resultado final do processo.

Ao longo do processo de compostagem também foram registradas avaliações de cinco parâmetros, dentre eles: insetos, moscas, larvas, minhocas e odor. Estes foram avaliados através dos cálculos das médias de acordo com cada fase da compostagem e a respectiva leira. Como pode ser observado nas figuras 3 , 4 e 5 .

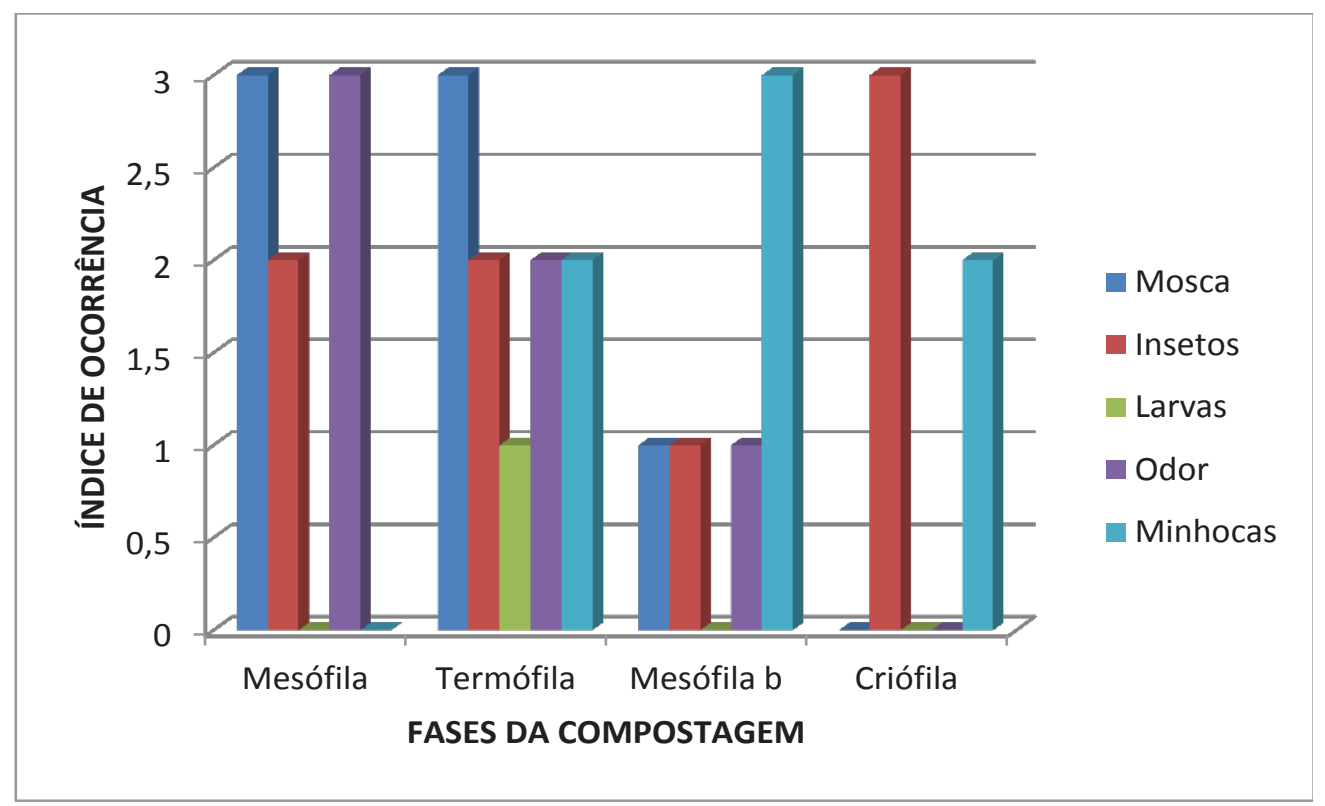

Figura 3: Parâmetros avaliados na leira 1. 


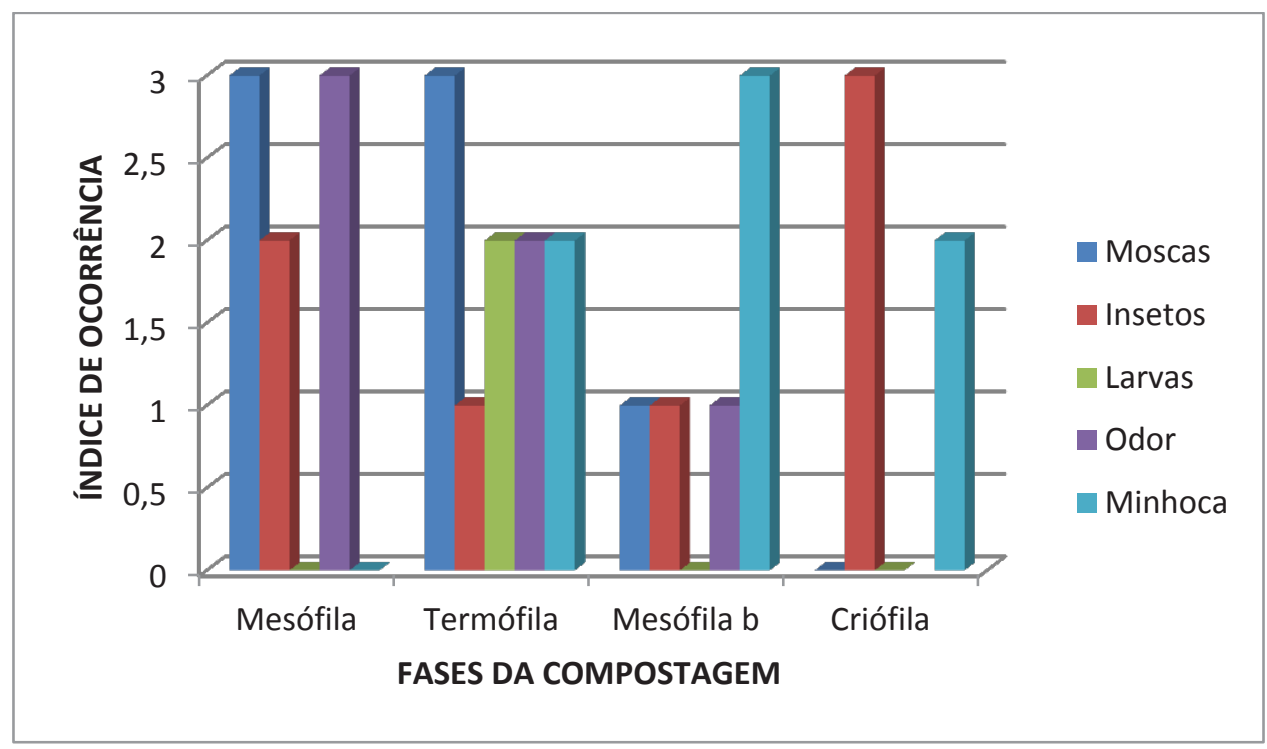

Figura 4: Parâmetros avaliados na leira 2.

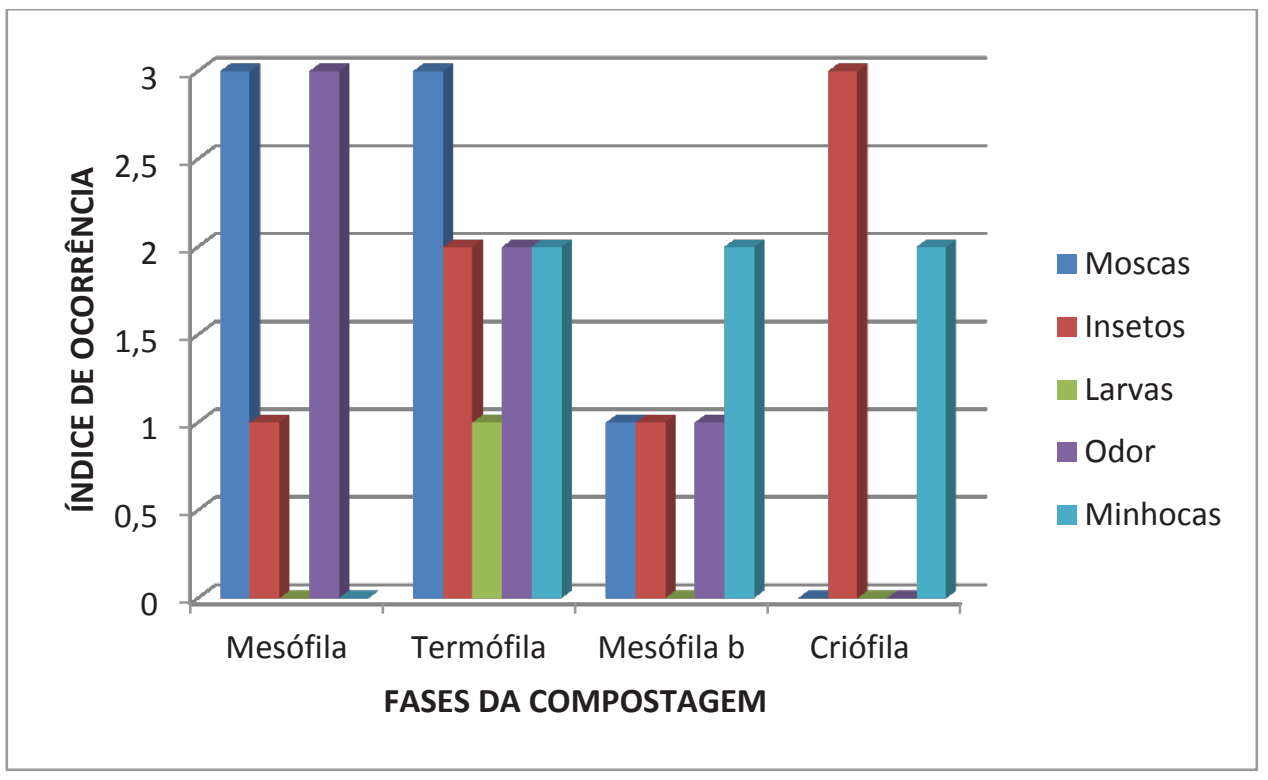

Figura 5: Parâmetros avaliados na leira 3.

Logo após a instalação do experimento verificou-se a intensa presença de moscas em todas as leiras, o que está relacionado ao odor do material utilizado, pois segundo Nakagawa (1992), o excesso de água (encharcamento) conjugado ao tipo de material utilizado na confecção das leiras causa a formação de odores, atraindo moscas. Observou-se que na fase mesófila e início da fase termófila, onde o composto apresenta maior teor de umidade, as moscas permaneceram por maior período no ambiente, não se constatando correlação com a maior presença e/ou permanência de larvas nas mesmas.

A presença de larvas foi verificada somente na fase inicial de compostagem, desaparecendo após passar pela fase termófila onde ocorre a destruição de ovos, larvas e microrganismos patogênicos (LIMA et al., 2011).

Já a presença de mosquitos, formigas e minhocas foram verificadas após o primeiro revolvimento, onde a exposição do material utilizado pode ter atraído os mesmos.

O odor pode ter sido ocasionado por falta de revolvimento, excesso de umidade, tamanho de partículas maior que $50 \mathrm{~mm}$ e forma geométrica inadequada da pilha (CARVALHO \& GUERRA, 20--?).

Conforme verificado, a presença de larvas, insetos e minhocas, ocorreu somente em peque- 
nas quantidades ao longo de alguns períodos da compostagem, o que está associado à utilização do composto Enzilimp, o qual segundo a Millenniun Tecnologia Ambiental, detentora da marca, é um biorremediador de esgotos para uso doméstico, que combate bactérias nocivas e evita infestação de insetos.

Atualmente, esta compostagem está entrando na fase criófila, onde nota-se apenas a presença de minhocas e insetos.

\section{CONCLUSÃO}

Pelos aspectos observados até o presente momento, conclui-se que a compostagem com o lodo do abatedouro de frangos Piovesan, mostra-se uma alternativa viável para o tratamento e destinação do mesmo. Em termos econômicos, sociais e ambientais os resultados se mostraram favoráveis, pois o lodo se transformará de um resíduo para um adubo orgânico, no qual poderá ser utilizado na agricultura.

A primeira fase mesófila ficou bem caracterizada pela presença do odor, moscas, insetos e larvas na fase inicial do processo de compostagem. Também pelas temperaturas registradas atingiu a fase termófila, sendo esta muito importante para a qualidade final do composto e a eficiência do processo.

O feno da grama Tifton, utilizado como fonte de carbono, não foi uma boa opção, sendo que o mesmo tem um processo de degradação mais lento que o lodo utilizado, seria mais viável e mais preciso utilizar um elemento que tivesse uma relação $\mathrm{C} / \mathrm{N}$ mais adequada.

Como o processo de compostagem não se encontra totalmente concluído, observaremos mais conclusões no final do processo que será de 120 dias.

\section{REFERÊNCIAS}

CARVALHO, S.T; GUERRA, M.A .de SL. Resíduos Sólidos: Compostagem. [20--?]. Disponível em: < http:// www.celso-foelkel.com.br/artigos/outros/10 Compostagem Cenibra.pdf >. Acesso em: 06 junho 2013.

KIEHL, E.J. Manual de compostagem: Maturação e qualidade do composto. Piracicaba - SP. Ed. Degaspari, $1998,171 \mathrm{p}$.

LIMA, C. dos S.; Porto Neto, F. de F.; Valadares, C. G.; Oliveira, A. da C.; Nascimento, D. O. do.; Araújo, V. M. de.; Custodio, L. R. Poluição do solo: alternativas viáveis para minimizar os impactos na região Nordeste. XI JORNADA DE ENSINO, PESQUISA E EXTENSÃO - JEPEX 2011 - UFRPE: Recife, 18 a 22 de outubro.

NAKAGAWA, J. Compostagem: obtenção e uso. In: Encontro Sobre Matéria Orgânica Do Solo: Problemas e Soluções, 1, 1992, Botucatu. Anais... Botucatu: Champion Papel e Celulose Ltda., 1992. 29p.

OLINTO, F. A.; Andrade, F. D.; Souza, J. R.; Silva, S. S.; Silva, G. D. Compostagem de resíduos sólidos. Revista Verde, Mossoró, RN, v. 7, n. 5, p. 40-44, 2012.

OLIVEIRA et al.,2008. Compostagem. Piracicaba- São Paulo. Disponível em: <http://www.agencia.cnptia. embrapa.br/Repositorio/Compostagem_000fhc8nfqz02wyi v80efhb2adn37yaw.pdf > . Acesso em: 08 junho 2013.

SUNADA, S. N. Efluente de abatedouro avícola: processos de biodigestão anaeróbia e compostagem. 2011. Disponível em : < http://www.ufgd.edu.br/fca/mestrado-zootecnia/dissertacoes/efluente-de-abatedouro-avicola-processos-de-biodigestao-anaerobia-e-compostagem-2013-natalia-da-silva-sunada-2013-2009-2011> Acesso em 08/06/2013 